\title{
Investigating of Mobile Learning Technology Acceptance in Companies
}

Laith T. Khrais, Department of Business Administration, College of Applied Studies and Community Services, Imam Abdulrahman Bin Faisal University Dammam, Saudi Arabia

Abdullah M. Alghamdi, Department of Management Information Systems, College of Applied Studies and Community Services, Imam Abdulrahman Bin Faisal University Dammam, Saudi Arabia

\begin{abstract}
Technology plays a prominent role enhancing and innovating the quality of work nowadays. Currently, the world is witnessing a new wave of industrial revolution driven by the development and diffusion of digital technology; for instance, the Internet of Things (IoT) is being used, adopted, and incorporated into people's everyday lives. Mobile learning, as one of the modern innovations, affects employee learning in the corporate world. Tools like CourseMill@ have critical significance due to its various benefits, such as enhance personal and convenience learning as information sharing, promote cooperation and collaboration in learning increasing management, bridge digital divide, and enhance job performance. However, numerous limitations of adopting mobile technologies were identified, such as high cost of implementation, unreliable broadband wireless connection, and shortcomings in mobile devices features like the small screen size. The study utilized both the Technology Acceptance Model (TAM) and the Unified Theory of Acceptance and Use of Technology model (UTAUT) to develop a research model to be used in the study. The multivariate exploratory factor analysis identified four main barriers that affect M-learning adoption, which is perceived usefulness (PU), perceived ease of use (PEU), social influences (SI), and facilitating conditions (FC). These factors have a significant positive influence on the acceptance and actual use of M-learning technology in companies.
\end{abstract}

Keywords: Mobile learning technology, M-learning adoption, E-learning, M-learning acceptance, TAM, UTAUT model.

\section{INTRODUCTION}

\section{M-learning in Companies}

Several forces are present that create a sense of pressure on the educational approach to get transformed for the future, a system that will drastically revolutionize the workplace environment and work nature. Among these forces is the 4 th Industrial Revolution, which constitutes a challenge for organizations. The rapid changes in technological advancements have necessitated the need for a knowledgeable, flexible, skillful, efficient, and competent workforce that would facilitate the attainment of goals and objectives and long-term organizational profitability [1]. Training of employees is a vital aspect in the development of competencies and skills necessary for excellent performance by organizations in combination with other factors, such as encouragement and motivation [2]. In [3], training of employees is getting more important day after another for many companies to gain a competitive advantage, growth, and for their survival, among other factors. The different departments in organizations rely on training, which provides help for their growth. Training outcomes affect the goals of employees and the organizations, and therefore, it is a fundamental human resource aspect necessary for attaining organizational success [3].

To increase productivity, training has been considered as a fundamental aspect for new employees concurrently with ongoing training of current employees is fundamental to help them adapt them be prepared to perform intended jobs, to improve performance and constant changes in the business environment [4]. Additionally, Cloutier et al. [5] argue that consistent training of employees helps in reducing resistance to change and thus promote growth. Therefore, it is prudent that organization heads and department leaders to work and devise measures that ensure systematic training of employees that incorporates advanced technologies.

One of the quickest ascending topics in business and IT is M-learning technology. One such M-learning tool is the CourseMill®; a highly rated learning management system used by organizations across the world. There is tremendous growth in the application of mobile learning in different institutions because 
of the associated advancement of low-cost technology [6]. Additionally, companies are increasingly adopting the use of portable devices like smartphones, PCs, and tablets. The increased ownership of portable devices has necessitated researches on how the devices can be used to promote the training of employees.

The M-learning sector of information technology has become appealing to different companies due to it possesses features such as cost-effectiveness and wide geographical distribution of materials through the automated system and open source systems. According to Lamptey and Boateng [7], insufficient financial resources in most small-sized companies minimize the extent to which technology is adopted companies. However, M-learning technology provides companies with a cost-effective measure to increase the training of staff and promote excellent performance and profitability of the respective companies [8]. Moreover, M-learning provides employees and organizational leadership with an interactive learning platform and promotes the discovery of more effective methods of learning [9].

The successful implementation of M-learning to facilitate the training of employees in different companies cannot be attained without the participation of the employees. The acceptance of mobile learning technology is dependent on the attitudes of the stakeholders, as [10] find that contended personal attitudes significantly influence how implemented technologies are utilized. Therefore, incorporation of attitudes is fundamental to developing an M-learning environment effective for organizations. To address the gap in the use of M-learning, this research aims to perform an empirical investigation of the factors that affect the acceptance of M-learning technology in companies. The research will apply the Technology Acceptance Model (TAM) as well as the Unified Theory of Acceptance and Use of Technology (UTAUT) in the development of its hypothesis.

The training of employees is becoming a fundamental success factor for organizations. Employee training is critical to countering the major problems that organizations face, such as insufficient knowledge and training, motivation and capabilities, lack of commitment, low turnover, and absenteeism among others [11]. M-learning provides an essential cost-effective measure for the organization to train employees and consequently promote profitability. However, acceptance of the M-learning technology significantly influences how the uses of the technology promote performance and, consequently, the profitability of the organization. In the Technology Acceptance Model (TAM), the user's perceived ease of using technology, which includes measures such as the amount of investment needed in adopting as well as the perceived usefulness like efficiency in task performance to a large extent determines how technology is successfully adopted [12]. Additionally, the UTAUT model finds that there are significant factors that affect the intentions of using M-learning, which includes self-management of learning, self-efficacy, attainment value, perceived enjoyment, quality of service, and ubiquity [13]. Therefore, the two models can be used to predict organizational acceptance and intension to use M-learning. The understanding of the different factors that affect M-learning among employees in various organizations is paramount to the management of the barriers in post-deployment. If the users are not willing to accept the technology, implementation will lead to non-use and the intended benefits will not be realized [14, 15]. Furthermore, [14] and [16] documents the importance of technology acceptance for successful usage. Therefore, acceptance of M-learning in companies is a key administration concern for all companies that are considering its implementation. Therefore, there is a need to investigate the factors that affect M-learning acceptance to help companies' device measures to promote successful implementation and realization of the intended benefits. Therefore, the study aims to: investigate factors that either support or constraints the use of M-learning in companies, investigate the factors that promote employee acceptance of Mlearning technology, to investigate the extent to which employees use M-learning resources for adequate learning.

In [17], corporate M-learning happens when organization employees are supported in their learning activities by portable computational devices. Learning takes place when an individual takes part in activities in a didactical framework leading to deeper understanding and skill acquisition [17]. Therefore, the use of mobile learning in companies is only considered effective when portable devices and knowledge shared leads to knowledge and skill acquisition.

The businesses in the modern-day global world operate in an era of learning and development [18]; therefore, employee training is a critical determinant of continuous positive performances. Considering the importance of training, M-learning also becomes critical for companies as it provides tools that enhance training amidst the advancement of the internet, technology, and globalization.

Traditionally, the stationary IT infrastructures in organizations facilitate employee training along with the implemented training programs. However, the employees in different corporations have poor access to the infrastructure hence the need for mobile technology to enhance agility [19, 20]. Additionally, there is an increase in the number of mobile employees given the rise in the internet and 
technology [17]. Consequently, mobile learning technology becomes more critical to address the limitation of access to the stationary IT infrastructure as well as address the need for mobile employees. Therefore, mobile learning will play a fundamental role in promoting learning-focused organizations.

There is also a significant change in the learning landscape within companies. In [21, 22], informal and work-based learning in organizations is gaining importance as most professional skills and competencies are gained through informal learning. Only a few employees find the formal sector to be effective sources of gaining specific knowledge necessary for excellent performance at the workplace [22, 23]. The changes in the learning landscape give M-learning importance to facilitate knowledge and skill acquisition among employees. M-learning technology gives employees autonomous access to information without necessarily needing to access stationary IT infrastructure at the organization.

There is broad acceptance that M-learning is effective learning technology. Globalization has, for instance, increased the acts of sending employees to work on assignments abroad [24]. Employees sent to work overseas require knowledge and skills needed to perform duties in foreign countries excellently. M-learning devices provide a significant opportunity for employees to get real-time training on how to handle assigned tasks in any location they are sent.

M-learning increases the abilities to integrate learning and work processes; therefore, there is an increased chance of applying the theoretical aspects learned into practice [25]. Additionally, M-learning improves the transfer of learning into work routines, as illustrated by [26]. M-learning technology is efficient in terms of costs and time [27]; therefore, it promotes learning while ensuring that the company remains profitable. There is an increased interest in the incorporation of mobile learning in companies; however, there are significant unresolved issues on the perspectives of companies and employees on the adoption of M-learning. For instance, increasing access and availability to mobile devices in an organization does not imply that staff will use them to learn. In [6], mobile phones have gained considerable interest in the fields of professional earning; however, there is relatively know knowledge on the effectiveness of the M-learning technologies to promote competence and learning in the work context. There is thus a need to understand the factors influencing the intention and actual use of $\mathrm{M}$ learning technology services by employees.

\section{Literature Review}

M-learning has mostly been implemented in learning institutions, and many studies have investigated the acceptance of technology by students [63]. However, M-learning is also applicable to corporations. There is a vast body of literature the indicates the importance of M-learning for corporations. Traxler and Vosloo [27] find while there is a global increase in the use of mobile technology, there is a growing interest in its application in education and training in different corporations. In [28], M-learning has been applied in companies to facilitate access to and production of learning material, increase learning communication and enhance the management of learning.

In $[29,30]$, the industrial training of employees using M-learning enhances learning by employees. The most essential and primary benefit of incorporating M-learning in companies is the portability of the devices. Portability of devices in M-learning removes the spatial and temporal limitation, which allows the employees and companies to effectively organize time and extend the access of course material, collaboration and communication as stated in [31]. Additionally, the continuous connectively encourages flexibility in accesses and increases engagement in knowledge sharing and learning, as indicated in ref. [32]. Similarly, [33, 34] find that ere are key benefits of M-learning; real-time file sharing, ease of management of electronic information, portability, and wireless connectivity that may make the technology appealing to corporations. M-learning allows for synchronized data storage, access, and sharing without necessarily having access to a stationary computer. The synchronized activities lead to the removal of barriers to learning and promote access to independent and collaborative learning. Furthermore, Stal and Paliwoda-Pękosz [32] claim that M-learning can bridge the digital divide by fostering collaborative learning, independence as well as enhance self-esteem and self-confidence. In this sense, M-learning promotes learning for employees, even when one does not have access to physical computers.

There is increased flexibility in M-learning, which extends learning into contextual ad authentic situations which facilitates lifelong learning, personalized activities, information seeking, and knowledge sharing through the provision of mobile devices and wireless access to communication, information, and research tools [19, 35]. For example, [36] suggests that the use of M-learning increases the likelihood of engaging in informal learning that is not tied to a physical location like a training workshop. Moreover, the uses of M-learning technology increase the abilities of users to have access to convenient, personalized, flexible, secure, and easy content interface [37]. Despite the significant advantages of using 
M-learning technology in companies, there are significant challenges that affect usability and acceptance. For instance, there are limitations on graphics, user-friendliness, small size keyboards, lower computational power, limited memory, slow downloading, small screen sizes, and short battery life [38, 39]. With these limitations, some users of M-learning technology will not find it convenient as their preferred mode of learning. As a result, the implementation of the technology in an organizational setting limits the realization of intended benefits. However, technological advancement can address the issues of usability, such as virtual keyboards [40].

The small screen size of portable devices causes eyestrain, makes viewing cumbersome, and limits usage by visually impaired users [41]. The portable devices also hamper the learning activities because of the limits in document editing and limited memory and storage [42]. While there are pages that allow users to make changes and edit documents, the small screen sizes, and small keyboards make the activities cumbersome. Therefore, M-learning is only as effective if the employees require minimum typing activities. Another factor that affects the implementation of mobile devices is the cost associated with implementation. Some studies [38, 43] cite that the high cost of implementing M-learning creates barriers to the use of technology by companies. Therefore, while companies may realize the increased benefits of using M-learning technology, some will be reluctant to adopt the technology because of the inability to afford. M-learning requires companies and their employees to have access to reliable Internet connectively. Unavailability of broadband wireless access prohibits the implementation of M-learning technology $[44,45]$. Thus, there is a need for IT infrastructure that ensures Internet connection in pure mobility mode. Without internet connection or with a significantly slow internet connection, the implementation of M-learning will not promote communication, sharing of information, and ultimately training of employees. Therefore, inadequate connectively in companies limits the usability of mobile devices and the realization of benefits.

The literature review indicated that there are numerous benefits of M-learning technology and the reason most corporations across the world are considering the use of technology. Literature shows no study has investigated the technology acceptance by employees in different companies. Yet, numerous companies are using M-learning to facilitate the training of employees for the identified benefits of the technology. There is little scientific evidence to support the use of M-learning in companies and associated upcoming trends. There is, therefore, a need to research to investigate M-learning acceptance in different companies.

\section{Theoretical Framework \\ Technology Acceptance Model (TAM)}

The technology acceptance model was first proposed by Davis in 1989 [46], but it has been improved over the years by different authors such as Agarwal and Prasad [47] and Moon and Kim [48]. Acceptance of new technology into an organization to a large extent determines the success of its implementation and its abilities to contribute positively and impact effectiveness on the system [46, 47]. Numerous models help in explaining the adoption of technology; however, TAM proposed by Davis remains to be the most used. The TAM is considered a fundamental paradigm for measuring the acceptance of new technology by users as it describes the antecedents of adopting IT. As shown in Figure1, TAM assumes factors that affect IT adoption, and they include perceived usefulness (PU) and perceived ease of use (PEU). The two factors jointly determine the behavioral intentions (PI), and the usage of IT adopted. When users perceive IT to ease and perceives the technology to be useful, then they are likely to adopt and use the technology. Furthermore, PEU use tends to lead to positive attitudes towards PU. Improvements of the model later included other variables, which include attitudes and behavioral intentions (PI). Figure 1 shows a summary of the TAM model in IT adoption. Notably, [48] added the variables, perceived enjoyment, which defines the engagement and performance activity from the intrinsic motivation of the user.

Fig. 1. TAM model

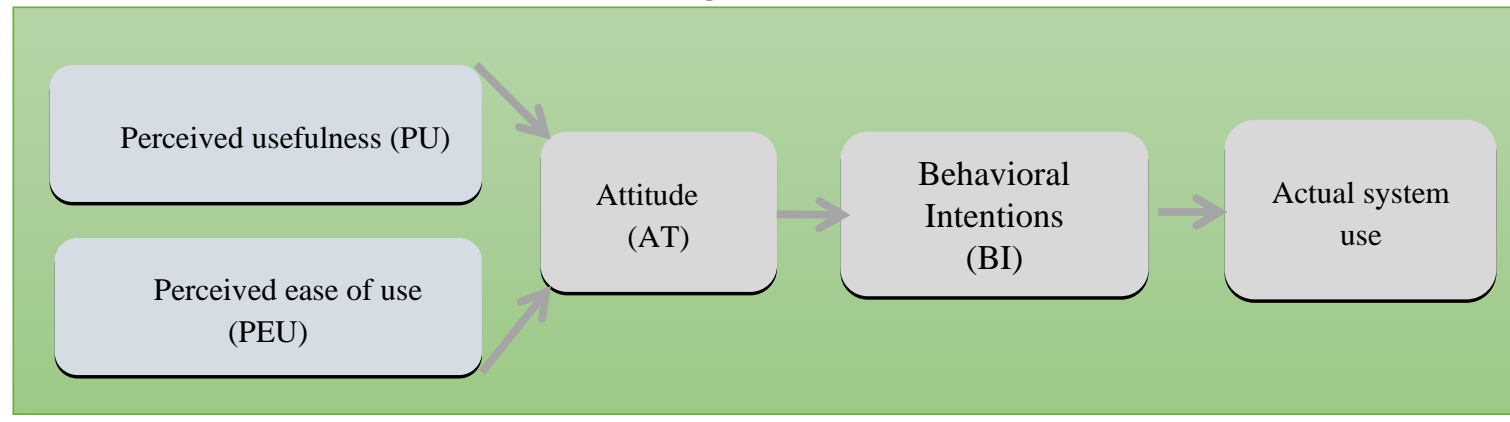




\section{Unified Theory of Acceptance and Use of Technology (UTAUT)}

UTAUT is another fundamental model in explaining technology adoption. Venkatesh et al. [49] recognized the importance of the user's perception in influence the acceptance of the technology. Venkatesh et al. [49] compared different models used to explain IT acceptance and developed the UTAUT model to synthesis provisions from other models.

Fig. 2. UTAUT model

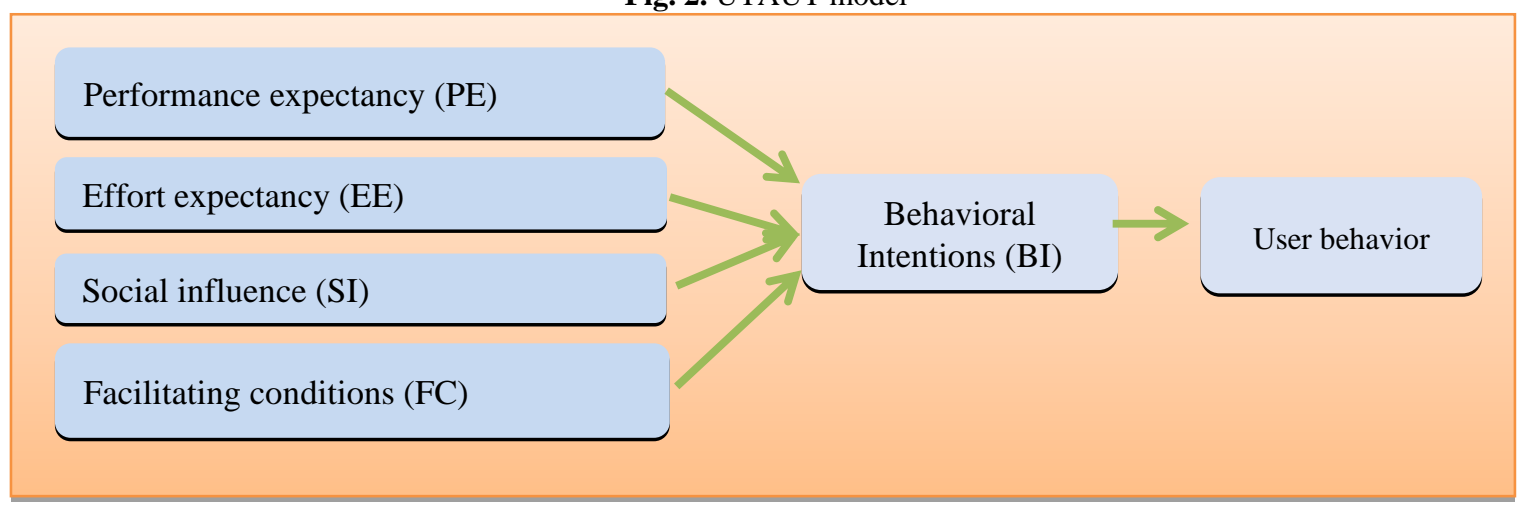

Figure 2 shows factors that affect technology acceptance on the UTAUT, which are; performance expectancy(PE), effort expectancy (EE), social influence (SI), facilitating conditions (FC). Notably, the impacts of the factors are moderated by age, gender, experience, and voluntariness Venkatesh et al. [49].

\section{The hypothesis from the theories}

Given the TAM and the UTAUT models, the acceptance of M-learning technology in companies is dependent on the variables, perceived usefulness/performance expectancy, perceived ease of use/effort expectancy, facilitating conditions, and social influences. Based on these variables, a hypothesis for this research can be derived, as illustrated in Figure 3, which demonstrates the developed research model for the current study.

Fig. 3. The proposed research model.

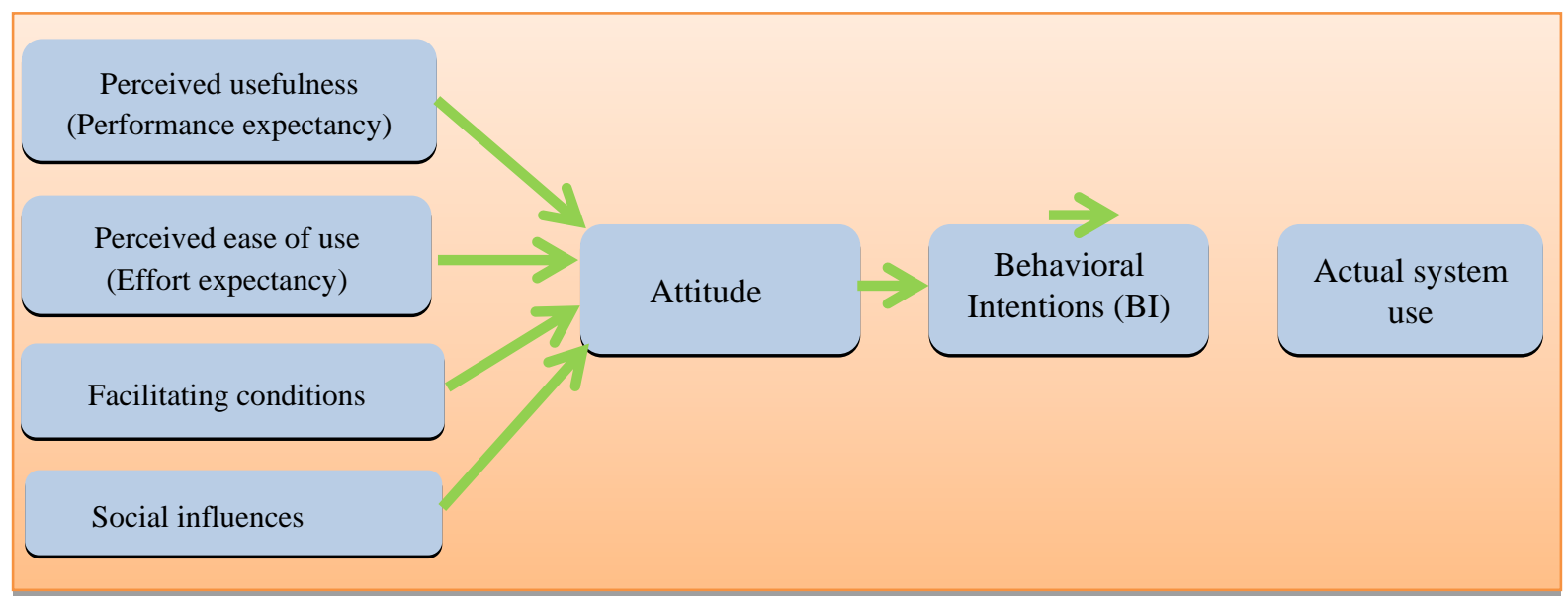




\section{Perceived usefulness (PU)}

According to Davis [46], PU is the extent to which users believe that the new technology will improve their job performance. The variable is similar to the PE from the UTAUT model Venkatesh et al. [49]. This research proposes that the adoption of M-learning will improve the job performance of employees in companies; hence the hypothesis:

H1: perceived usefulness increases acceptance of M-learning in companies and consequently, the actual use of the system.

\section{Perceived ease of use (PEU)}

Davis [46] asserts that PEU as the degree of ease when users utilize a given technology. The variable is similar to the EE in the UTAUT model Venkatesh et al. [49]. In this context, the authors assume that simple systems that are easy to use enhances usability and consequently performance, hence the hypothesis formed:

H2: perceived ease of use will increase acceptance of M-learning in companies and consequently actual use of the system.

\section{Social influences (SI)}

Venkatesh et al. [49] define SI as the extent to which a user believes that others find it necessary for them to use the new system. SI significantly influences BI and consequently, the use of a new system. Hence the hypothesis.

H3: social influences lead to acceptance of M-learning in companies and consequently actual use of the system.

\section{Facilitating conditions (FC)}

The FC in Venkatesh et al. [49] describes all the resources that are required to perform activities such as money and time. The availability of resources has significant positive impacts on the usability of implemented technology. For instance, the provision of technical help to employees during deployment of M-learning will enhance the functionality of the devices as well as its usage. Hence, H4: facilitating conditions increase acceptance of M-learning in companies and consequently, the actual use of the system.

\section{Methodology \\ Research Paradigm}

Research paradigms outline the different assumptions that researchers follow when conducting research, see ref [50], [51]. This research uses a positivist approach, which states that realities are measurable, and thus, it uses a quantitative approach. The phenomenon being studied in the research is technology acceptance in companies. The positivist's approach necessitates the testing of hypotheses to measure truths objectively. The theoretical framework used in the study facilitated the development of four hypotheses which will be tested using the positivist's approach. Here, factual information will be constrained to the quantitative data collected.

\section{Research Approach}

The positivist approach necessitates the use of quantitative research, which uses empirical measures to investigate a phenomenon using computational, statistical, and mathematical approaches, see ref. 52 . According to [53], the quantitative data obtained facilitates the establishment of the connection between empirical observations and the hypotheses developed. Data on perceived usefulness, perceived ease of use, facilitating conditions, and social influences will be collected and measured to investigate whether they are in line with the hypotheses of the study. The research will use the deductive reasoning approach, which concerns hypothesis testing. The deductive reasoning strategy is the most effective for use in this quantitative research as it facilitates the investigation of whether a hypothesis is true or false, sees [54].

\section{Sampling}

The target populations for this research were employees working in different corporations. Notably, participants were limited to the employees whose organizations have considered and implemented Mlearning as a strategy that increases the training of employees. When using a quantitative approach, it is almost impossible to use a whole population when doing research, see [55]. In [56], a sample size between 30 and 500 is appropriate for research. In [57], there are many different sampling techniques; however, this study used convenience sampling. In this sampling technique, participants will constitute individuals that are accessible and willing to participate in the research. 


\section{Instrumentation}

Descriptive research used a survey method for data collection. The research used questionnaires constituting of 16 questions. The survey questions were divided into two sections. The first section collected the demographic information about the participants, which included gender, age, position in employment, and experience in M-learning. While the second section of the survey questions constituted 12 questions that were developed from the constructs; perceived usefulness (PU), perceived ease of use (PEU), social influences (SI), and facilitating conditions (FC). The specific variables targeted in the different questions included support from the institution, availability of time, and money (facilitating conditions), job performance, increase productivity and enhance the ability to complete assignments faster (perceived usefulness), influence by friends, influence by the organization, and self-confidence (social influences), and ease of use, flexibility, and clear understanding of the M-learning tool (perceived usefulness). The measurement of items in the questionnaire was done using a five-point Likert scale to allow the participants to express their opinion on how much they agree or disagree with the different statements made. The points on the Likert scale are defined as follows: strongly agree, agree, neutral, disagree, and strongly disagree. The developed questionnaire was written in English, proofread, and expert opinion sought before its actual use. The expert opinion was prudent in making the research more authentic and scientific, and therefore, findings are made more reliable.

\section{Data Collection Methods/Tools and Sources}

The data was collected using online platforms, including LinkedIn, WhatsApp, Google, and Facebook. Notably, the individual participants were sent letters informing them about the study, the importance of their participants, and their rights to opt-out of the study any time they wished to. Notably, the research participants were asked to enhance confidentiality and privacy by not providing personally identifiable information. Table 1 gives a summary of the sample collected and the demographic data.

Table 1. Participants ( $\mathrm{n}=78$ )

\begin{tabular}{|l|l|l|l|}
\hline Variable & Description & $\begin{array}{l}\text { Number of } \\
\text { Respondents }\end{array}$ & $\begin{array}{l}\text { Percentage } \\
\text { (\%) }\end{array}$ \\
\hline \multirow{3}{*}{ Gender } & Male & 42 & 52.8 \\
\cline { 2 - 4 } & Female & 36 & 46.2 \\
\hline \multirow{5}{*}{ Age } & $19-23$ & 11 & 14.1 \\
\cline { 2 - 4 } & $24-30$ & 28 & 35.9 \\
\cline { 2 - 4 } & $31-40$ & 25 & 32.1 \\
\cline { 2 - 4 } & Above 40 & 14 & 17.9 \\
\hline \multirow{5}{*}{ Position } & Managerial & 6 & 7.7 \\
\cline { 2 - 4 } & Supervisors & 11 & 78.1 \\
\cline { 2 - 4 } & Ordinary Employee & & 17.9 \\
\hline \multirow{3}{*}{ Experience } & Good M-learning & 14 & 27.7 \\
\cline { 2 - 4 } & Average M-learning & 45 & 24.4 \\
\cline { 2 - 4 } & Bad M-learning & 19 & \\
\hline
\end{tabular}

\section{Data Analysis}

The data collected were combined in SPSS v.22 and AMOS v.17, where all the data analysis was performed. Since the data collected was ordinal as it used a Likert scale, then the data used in the research is non-parametric. The statistical analysis performed was multivariate factor analysis.

\section{Results and Findings}

The data collected from the survey were examined using the exploratory factor analysis (EFA). All the constructs from the research model were included in the EFA analysis and that AMOS v.17 was used to assess the validity and reliability of the data. Verification of the discriminant and convergent as well as their reliability to ensure the model is fit for testing the hypothesis. In [61], convergent validity is verified when composite reliability is more than 0.8 , the average variance extracted (AVE) is more than 0.5 , and the factor loading is more than 0.5. In [62], the minimum acceptable value of Cronbach alpha should be 0.60 . Table 2 gives a summary output and confirmation of validity.

Table 2. Confirmatory factor analysis

\begin{tabular}{|l|l|l|l|l|l|}
\hline Variable & Item & Estimate & AVE & Composite & Cronbach \\
\hline
\end{tabular}




\begin{tabular}{|c|c|c|c|c|c|}
\hline & & & $(0.5)$ & $\begin{array}{l}\text { Reliability } \\
(.0 .8)\end{array}$ & Alpha (.0.6) \\
\hline \multirow{3}{*}{ Perceived usefulness } & PU1 & 0.89 & \multirow{3}{*}{0.77} & \multirow{3}{*}{0.94} & \multirow{3}{*}{0.94} \\
\hline & PU2 & 0.88 & & & \\
\hline & PU3 & 0.88 & & & \\
\hline \multirow{3}{*}{ Perceived ease of use } & PEU1 & 0.87 & \multirow{3}{*}{0.76} & \multirow{3}{*}{0.93} & \multirow{3}{*}{0.93} \\
\hline & PEU2 & 0.86 & & & \\
\hline & PEU3 & 0.88 & & & \\
\hline \multirow[t]{3}{*}{ Social Influences } & SI1 & 0.86 & \multirow{3}{*}{0.70} & \multirow{3}{*}{0.90} & \multirow{3}{*}{0.90} \\
\hline & SI2 & 0.87 & & & \\
\hline & SI3 & 0.82 & & & \\
\hline \multirow[t]{3}{*}{ Facilitating conditions } & FC1 & $\begin{array}{l}0.83 \\
\end{array}$ & \multirow{3}{*}{0.74} & \multirow{3}{*}{0.92} & \multirow{3}{*}{0.92} \\
\hline & FC2 & 0.844 & & & \\
\hline & FC3 & 0.89 & & & \\
\hline
\end{tabular}

From the results, all Cronbach alphas were more than 0.9; therefore, valid as they are above the minimum value of 0.6. Additionally, Fornell \& Larcker [61] suggest that the square root of the AVE of a given construct can be calculated to assess the discriminant validity. The summary of the square root analysis is examined in Table 3.

Table 3. Discriminant validity

\begin{tabular}{|l|l|l|l|l|}
\hline Construct & PU & PEU & SI & FC \\
\hline PU & $\mathbf{0 . 8 8}$ & & & \\
\hline PEU & 0.33 & $\mathbf{0 . 8 7}$ & & \\
\hline SI & 0.61 & 0.36 & $\mathbf{0 . 8 4}$ & \\
\hline FC & 0.29 & 0.39 & 0.20 & $\mathbf{0 . 8 6}$ \\
\hline
\end{tabular}

From Table 3, there is discriminant validity as illustrated by the higher values of the square roots in bold compared to corresponding values.

The structural modeling equation was then conducted to examine the relationship between the constructs and coefficients necessary for testing the hypotheses. The summary of the output from the structural modeling fit is illustrated in Table 4.

Table 4. Evaluation of model and fitness measure

\begin{tabular}{|l|l|l|}
\hline Measure & Suggested values & Observed values \\
\hline Root mean square residual (RMM) & $<0.05$ & $<0.04$ \\
\hline $\begin{array}{l}\text { Root mean square errors of approximation } \\
\text { (RMSEA) }\end{array}$ & $<0.05$ or 0.08 & $<0.03$ \\
\hline Goodness of fit index (GFI) & $>0.9$ & $>0.92$ \\
\hline
\end{tabular}

From Table 4, the model measurement test showed that the data displayed a good fit with the proposed measurement model. The structural modeling analysis at 0.001 levels and 0.05 level were used to test the hypothesis developed. ${ }^{*}$ indicate measures at 0.5 level while ${ }^{* *}$ indicate measures done at 0.001 level. Table 5 gives a summary of the output from the hypothesis testing.

Table 4. Hypothesis testing

\begin{tabular}{|c|c|c|c|c|}
\hline Hypot Hypothesis & $\begin{array}{l}\text { Standard Path } \\
\text { coefficients }(\beta)\end{array}$ & T-Value & Significance & Support \\
\hline $\begin{array}{l}\text { H1: PU leads to actual } \\
\text { M-learning system use }\end{array}$ & $0.631^{* *}$ & 14.326 & $\mathrm{P}<0.001$ & Yes \\
\hline $\begin{array}{l}\text { H2: PEU leads to } \\
\text { actual M-learning } \\
\text { system usage }\end{array}$ & $\begin{array}{l}0.16^{*} \\
0.16^{*}\end{array}$ & 8.011 & $\mathrm{P}<0.05$ & Yes \\
\hline $\begin{array}{l}\text { H3: SI leads to actual } \\
\text { M-learning system } \\
\text { usage }\end{array}$ & $0.261^{* *}$ & 8.113 & $\mathrm{P}<0.001$ & Yes \\
\hline
\end{tabular}


Results from Table 5 indicate that all the constructs measured in the research; PU, PEU, FC, and SI had significant positive impacts, and hence the hypotheses were accepted. The studies support the acceptance of M-learning and, consequently, its actual usage in companies.

\section{Discussion of Results}

The research aimed to investigate the factors that affect M-learning acceptance and how M-learning technology affects employees in different companies. The specific objectives of the research were to examine factors supporting or constraining M-learning implementation, factors promoting employee acceptance of M-learning technology, and the extent to which employees use M-learning resources for adequate learning.

Numerous studies, [27-37], provide advantages of M-learning for companies and they include increased information sharing, increasing management of learning, enhance job performance, bridging the digital divide, and promote collaboration and cooperation in learning, and improved convenience and personalized learning. However, some studies find significant limitations with M-learning, see [38-45], such as shortcomings in mobile devices features like the small screen size, unreliable broadband wireless connection, and high cost of implementation. The research used the TAM and UTAUT models to develop a hypothesis for the examination of the research objectives. The research model identified four constructions which include perceived usefulness, perceived ease of use, social influences, and facilitating conditions. The hypothesis found that all four constructs influence M-learning acceptance and, consequently, its usage in companies. The results from the study indicated that the employee PU, PEU, SI, and FC had a significant positive impact on the actual use of M-learning technology in companies. The strong relationship between the constructs the acceptance of a technological model was also evidence in the Davis in 1989 [46], Agarwal and Prasad [47], Moon and Kim [48], Venkatesh et al. [49]. This finding implies that the increased acceptability of M-learning technology is affected by numerous factors forming up the constructs in the model.

Negative variables constraints the implementation of M-learning in companies, while positive variables contribute to the acceptance of M-learning technology. For instance, FC such as support from the institution, availability of time, and the money supports the acceptance and use of M-learning technology while the limitations of these variables such as lack of support from the institution, lack of time, and inadequate funds constraints the implementation of M-learning technology. The same case is true for the other three variables. All the variables that are supporting implementation also support acceptance of the M-learning model by the employees in companies. For instance, PU such as the ability of M-learning to improve job performance, increase productivity, and enhance the ability to complete assignments faster would promote acceptance. In contrast, perceptions that the M-learning would not improve performance, productivity, or abilities to complete tasks more quickly would hinder acceptance. The extent to which the employees in the companies use M-learning resources for adequate learning is dependent upon the acceptance level. SI such as influence by friends influence by the organization, and self-confidence as well as perceived ease of use variables like ease of use, flexibility, and clear understanding of the M-learning tool contributes to an increased acceptance and use of the technology.

\section{Conclusion}

The research demonstrated the factors that affect the acceptance of M-learning among employees in the corporate world. An increased understanding of the factors determining the acceptance of the M-learning technology enables corporations to incorporate insights into the design and implementation phase, which is critical for the successful delivery of the technology and realization of intended benefits. From the literature, it is evident that if employees are not able to accept M-learning technology, they will not use it to promote learning maximally.

\section{Contribution to the Field}

The literature found that there is little evidence to show the incorporation of M-learning technology in companies in line with the upcoming trends where companies are increasingly employing the technology. This study adds to the literature as it gives scientific evidence to support M-learning in companies and the need to consider all factors that affect acceptance of M-learning technology.

The study also provides company heads with insights on how they can successfully implement Mlearning to make the technology effective in influencing productivity. For instance, company leaders need SI that promoting awareness of benefits and promote FC by providing all necessary tools that will 
promote the use of the M-learning technology. The research also has implications for designers of Mlearning tools for use in companies such as Coursemill@. Particularly, the designers need to invent tools that promote ease of use and maximum benefits on job performances.

\section{Future Research}

The study investigates M-learning acceptance from the employee's perspective. There is, therefore, a need to investigate how M-learning acceptance in different departments in corporations such as sales, research and development, and human resource departments, among others. The investigation of $\mathrm{M}$ learning from a department perspective will give significant insights and a better understanding of the technology and its adoption. The identified limitations of this study include sample size and the sampling technique. This research recommends that the same study be conducted using a random sampling technique and a larger population. Additionally, a longitudinal study can be prudent in examining the long-term changes in M-learning technology as used in companies to enhance job performances.

\section{References}

[1] A., Sarabi, F. J. Froese, and M. Hamori. (2017). Is inpatriate assignment experience a ticket to the top of a foreign subsidiary? The moderating effect of subsidiary context. Journal of World Business, vol 52, no. 5. [Online Serial]. Available: https://www.sciencedirect.com/science/article/abs/pii/S1090951617304443 [Accessed May 13, 2020].

[2] Agarwal, R., \& Prasad, J. (1998). The antecedents and consequents of user perceptions in information technology adoption. Decision support systems, 22(1), 15-29.

[3] Alakrash, H. M., Razak, N. A., \& Bustan, E. S. (2020). The Effectiveness Of Employing Telegram Application In Teaching Vocabulary: A Quasai Experimental Study. Multicultural Education, 6(1).

[4] Alepis, E., \& Virvou, M. (2014). Object-oriented user interfaces for personalized mobile learning. Springer.

[5] Alghamdi, A. M. (2017). The Potential of Adopting Smart Mobile Tools for Learning and Teaching Activities in Saudi Universities (Doctoral dissertation, University of Lincoln).

[6] Al-Hunaiyyan, A., Alhajri, R. A., \& Al-Sharhan, S. (2018). Perceptions and challenges of mobile learning in Kuwait. Journal of King Saud University-Computer and Information Sciences, 30(2), 279-289.

[7] Ally, M., Samaka, M., Impagliazzo, J., Mohamed, A., \& Robinson, M. (2014, November). Workplace learning using mobile technology: a case study in the oil and gas industry. In International Conference on Mobile and Contextual Learning (pp. 250-257). Springer, Cham.

[8] Al-Said, K. M. (2015). Students' Perceptions of Edmodo and Mobile Learning and Their Real Barriers towards Them. Turkish Online Journal of Educational Technology-TOJET, 14(2), 167-180.

[9] Antwi, S. K., \& Hamza, K. (2015). Qualitative and quantitative research paradigms in business research: A philosophical reflection. European journal of business and management, 7(3), 217-225.

[10] Ashraf, A. R., Thongpapanl, N., \& Auh, S. (2014). The application of the technology acceptance model under different cultural contexts: The case of online shopping adoption. Journal of International Marketing, 22(3), 68-93.

[11] Asiimwe, E., \& Hatakka, M. (2017). Practices and challenges in an emerging m-learning environment. International Journal of Education and Development using ICT, 13(1).

[12] Bere, A., \& Rambe, P. (2019). Understanding Mobile Learning Using a Social Embeddedness Approach: A Case of Instant Messaging. International Journal of Education and Development using Information and Communication Technology, 15(2), 132-153.

[13] Chatterjee, S., Sarker, S., \& Siponen, M. (2017). How do mobile ICTs enable organizational fluidity: toward a theoretical framework. Information \& Management, 54(1), 1-13.

[14] Chee, K. N., Ibrahim, N. H., Yahaya, N., Surif, J., Rosli, M. S., \& Zakaria, M. A. Z. M. (2017). A review of literature in mobile learning: A new paradigm in teaching and learning pedagogy for now and then. Advanced Science Letters, 23(8), 7416-7419.

[15] Chen, N. S., Cheng, I. L., \& Chew, S. W. (2016). Evolution is not enough: Revolutionizing Current learning environments to smart learning environments. International Journal of Artificial Intelligence in Education, 26(2), 561-581.

[16] Cloutier, O., Felusiak, L., Hill, C., \& Pemberton-Jones, E. J. (2015). The Importance of Developing Strategies for Employee Retention. Journal of Leadership, Accountability \& Ethics, 12(2).

[17] da Costa, D. D., \& de Lhanguene, U. (2014). Views of Informal Work-Based Learners during the Acquisition of Vocational Skills in Economically Deprived Suburban Settings In Mozambique. The African Journal for Work-Based Learning, 31.

[18] Davies, C., \& Fisher, M. (2018). Understanding research paradigms. Journal of the Australasian Rehabilitation Nurses Association, 21(3), 21.

[19] Davis, F. D. (1989). Perceived usefulness, perceived ease of use, and user acceptance of information technology. MIS quarterly, 319-340. 
[20] El Hariry, N. A. (2015). Mobile phones as useful language learning tools. European Scientific Journal, 11(16), 298-317.

[21] Engelmann, A., \& Schwabe, G. (2018). Enabling Workers to Enter Industry 4.0: A Layered Mobile Learning Architecture. In Proceedings of the 51st Hawaii International Conference on System Sciences.

[22] Eysenbach, G., \& Wyatt, J. (2002). Using the Internet for surveys and health research. Journal of Medical Internet Research, 4(2), e13.

[23] Fornell, C., \& Larcker, D. F. (1981). Structural equation models with unobservable variables and measurement error: Algebra and statistics.

[24] Glen, R., Suciu, C., \& Baughn, C. (2014). The need for design thinking in business schools. Academy of Management Learning \& Education, 13(4), 653-667.

[25] Hair, J. F., Black, W. C., \& Babin, B. J. (2010). RE Anderson Multivariate data analysis: A global perspective. New Jersey, Pearson Prentice Hall, 661-699.

[26] Hsieh, P. J. (2015). Healthcare professionals' use of health clouds: Integrating technology acceptance and status quo bias perspectives. International journal of medical informatics, 84(7), 512-523.

[27] Huang, Y. (2014). An empirical analysis of factors impacting mobile learning acceptance in higher engineering education.

[28] Huang, Y. (2014). An empirical analysis of factors impacting mobile learning acceptance in higher engineering education.

[29] Jackson, D. (2015). Employability skill development in work-integrated learning: Barriers and best practice. Studies in Higher Education, 40(2), 350-367.

[30] Jacob, S. M., \& Issac, B. (2014). Mobile devices and their mobile learning usage analysis. arXiv preprint arXiv:1410.4375.

[31] Krotov, V., Junglas, I., \& Steel, D. (2015). The mobile agility framework: an exploratory study of mobile technology enhancing organizational agility. Journal of theoretical and applied electronic commerce research, 10(3), 1-7.

[32] Lai, P. C. (2017). The literature review of technology adoption models and theories for the novelty technology. JISTEM-Journal of Information Systems and Technology Management, 14(1), 21-38.

[33] Lamptey, H. K., \& Boateng, R. (2017). Mobile learning in developing countries: A synthesis of the past to define the future. International Journal of Social, Behavioral, Educational, Economic, Business and Industrial Engineering, 11(2), 420-427.

[34] Lawrence, B. (2015). Learner Receptiveness Towards Mobile Technology in a College English Program: The Smart Decision?. English Teaching, 70(1).

[35] Ling, L., \& Ling, P. (2017). Methods and paradigms in education research. Teaching and Learning, 2021, 299.

[36] Marusic, A., Wager, E., Utrobicic, A., Rothstein, H. R., \& Sambunjak, D. (2016). Interventions to prevent misconduct and promote integrity in research and publication. Cochrane Database of Systematic Reviews, (4).

[37] Minshall, S. (2018). Evaluating the effect of display size on the usability and the perceptions of the safety of a mobile handheld application for accessing electronic medical records (Doctoral dissertation).

[38] Moon, J. W., \& Kim, Y. G. (2001). Extending the TAM for a World-Wide-Web context. Information \& management, 38(4), 217-230.

[39] Navarro, C. X., Molina, A. I., Redondo, M. A., \& Juárez-Ramírez, R. (2016). Framework to evaluate mlearning systems: A technological and pedagogical approach. IEEE Revista Iberoamericana de Tecnologias del Aprendizaje, 11(1), 33-40.

[40] Noe, R. A., Hollenbeck, J. R., Gerhart, B., \& Wright, P. M. (2015). Human resource management. Gaining a Competitive.

[41] Nunnally, J. C. (1978). Psychometric Theory: 2d Ed. McGraw-Hill.

[42] Pimmer, C., \& Gröhbiel, U. (2008). Mobile Learning in corporate settings. Results from an Expert Survey. In International conference on mobile learning. mLearn (pp. 250-257).

[43] Pimmer, C., \& Pachler, N. (2014). Mobile learning in the workplace: Unlocking the value of mobile technology for work-based education. Increasing access through mobile learning, 193-203.

[44] Prasad, R. (2020). Mobile learning for sales and service personnel: Case studies in the corporate training environment (Doctoral dissertation, Lancaster University).

[45] Rashevska, N., \& Tkachuk, V. (2015). Technological conditions of mobile learning at high school. Metallurgical and mining industry, 3, 161-164.

[46] Raymond, N. A. (2017). Beyond "do not harm" and individual consent: Reckoning with the emerging ethical challenges of civil society's use of data. In Group Privacy (pp. 67-82). Springer, Cham.

[47] Riffe, D., Lacy, S., \& Fico, F. (1998). Quantitative content analysis. 
[48] Saks, A. (2015). Managing Performance Through Training \& Development, (Canadian ed.). Nelson Education.

[49] Sarrab, M., Elbasir, M., \& Alnaeli, S. (2016). Towards a quality model of technical aspects for mobile learning services: An empirical investigation. Computers in Human Behavior, 55, 100-112.

[50] Schutt, R. K. (2018). Investigating the social world: The process and practice of research. Sage publications.

[51] Sekaran, U., \& Bougie, R. (2016). Research methods for business: A skill-building approach. John Wiley \& Sons.

[52] Shelton, C. (2017). Giving up technology and social media: why university lecturers stop using technology in teaching. Technology, Pedagogy, and Education, 26(3), 303-321.

[53] Shen, R. (2014). Constructing a user experience-based mobile learning environment: problems and solutions (Doctoral dissertation, FernUniversität in Hagen).

[54] Srivastava, S., \& Gulati, V. P. (2014). M-Learning--On Path to Integration with Organisation Systems. International Association for the Development of the Information Society.

[55] Stal, J., \& Paliwoda-Pękosz, G. (2016). Why M-Learning Might Appeal to Organisations?. In Proceedings of the 13th European, Mediterranean \& Middle Eastern Conference on Information Systems (pp. 139-148).

[56] Stal, J., \& Paliwoda-Pękosz, G. (2016). Why M-Learning Might Appeal to Organisations?. In Proceedings of the 13th European, Mediterranean \& Middle Eastern Conference on Information Systems (pp. 139-148).

[57] Storey, J. (2014). New Perspectives on Human Resource Management (Routledge Revivals). Routledge.

[58] Sung, S. Y., \& Choi, J. N. (2014). Do organizations spend wisely on employees? Effects of training and development investments on learning and innovation in organizations. Journal of organizational behavior, 35(3), 393-412.

[59] Traxler, J., \& Vosloo, S. (2014). Introduction: The prospects for mobile learning. Prospects, 44(1), 13-28.

[60] Tyrer, S., \& Heyman, B. (2016). Sampling in epidemiological research: issues, hazards, and pitfalls. BJPsych Bulletin, 40(2), 57-60.

[61] Van Noy, M., James, H., \& Bedley, C. (2016). Reconceptualizing learning: A review of the literature on informal learning. ACT Foundation. Rutgers Education and Employment Research Center.

[62] Venkatesh, V., Morris, M. G., Davis, G. B., \& Davis, F. D. (2003). User acceptance of information technology: Toward a unified view. MIS quarterly, 425-478.

[63] Woodill, G. (2014). Unique affordances of mobile learning. Mastering Mobile Learning, 111-126.

[64] Zimmerman, H. T., \& Land, S. M. (2014). Facilitating place-based learning in outdoor informal environments with mobile computers. TechTrends, 58(1), 77-83. 